\title{
НАРУШЕНИЯ ПИТАНИЯ У ПАЦИЕНТОВ, ПОЛУЧАЮЩИХ ЛЕЧЕНИЕ ГЕМОДИАЛИЗОМ
}

\author{
Щербаков Е.В., Пятченков М.О., Нагибович О.А., Шипилова Д.А. \\ ФГВБОУ ВО «Военно-медицинская академия им. С.М. Кирова» МО РФ, Санкт-Петербург
}

ЦЕЛЬ: изучить встречаемость разных видов нарушений питания (ожирение, избыточное питание, белково-энергетическая недостаточность (БЭН)) у больных с хронической болезнью почек 5 стадии, получающих лечение гемодиализом (ХБП С5 (Д)).

МАТЕРИАЛЫ И МЕТОДЫ: обследовано 65 человек (45 мужчин и 20 женщин), получавших лечение программным гемодиализом по стандартной схеме 4 часа 3 раза в неделю. Доза диализа у всех больных была адекватной: KT/V 1,2-1,5. Средний возраст пациентов составил 60,5 13,6 лет, продолжительность заместительной почечной терапии - от 1 до 8 лет. Основными причинами ХБП С5 были хронический гломерулонефрит (28 (43\%)) и сахарный диабет 2 типа (14 (22\%)). Нарушения питания устанавливали по данным антропометрического исследования и биоимпендансометрии с помощью анализатора «InBody 720» компании Biospace (Корея). Дополнительно вычисляли индекс жировой массы тела (ИЖМ), рассчитанный как отношение жировой массы тела (кг) к квадрату роста (м²). За норму для мужчин принимали значение

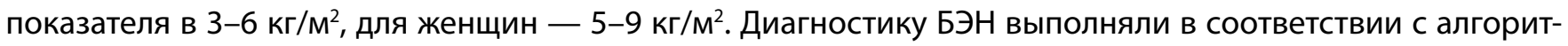
мом, предложенным International Society of Renal Nutritionand Metabolism (ISRNM). Данные представлены в виде среднего значения (M) и стандартного отклонения (s). Сравнение относительных частот внутри одной или в двух группах проводили с использованием «Вероятностного калькулятора» в программе «Statistica 6.0». Различия считались статистически значимыми при p $<0,05$.

РЕЗУЛЬТАТЫ: ожирение диагностировано у 24 пациентов (19 мужчин, 5 женщин), что составило 36,9\% от общего числа обследованных. Из них критериям ожирения 1 степени соответствовали 17 (26,2\%) больных, что превышало частоту встречаемости ожирения 2 и 3 степени (6,2\% и 4,6\% соответственно, p $<0,05)$. Среднее отношение окружности талии к окружности бедер в обследованной группе больных

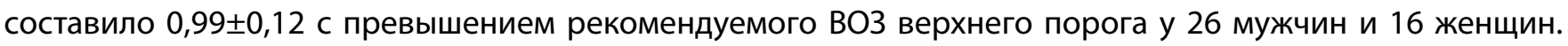
Абдоминальное ожирение встречалось у 65\% пациентов и чаще наблюдалось, чем его отсутствие (35\%, p<0,05). Индекс массы тела в диапазоне 25-29,9 кг/м² (избыточное питание) имели 22 (33,9\%) больных (16 мужчин и 6 женщин), что не превышало частоту ожирения. По результатам биоимпендансометрии обнаружено превышение ИЖМ тела у 36 из 45 (80\%) мужчин и у 11 из 20 (55\%) женщин. Показатель области жира внутренних органов, свидетельствующий о наличии избыточной висцеральной жировой ткани, был повышен у 50 (77\%) больных (38 мужчин и 12 женщин). Встречаемость БЭН в обследованной выборке пациентов составила 12,3\% (4 мужчин и 4 женщин), что было существенно ниже $(p<0,05)$ по сравнению с другими нарушениями питания.

ВЫВОды: среди нутритивных расстройств у больных с ХБП С5, получавших лечение гемодиализом, преобладали ожирение 1 степени и избыточное питание, выявляемые более чем у половины пациентов, что по данным литературы ассоциировано с лучшей выживаемостью. Напротив, абдоминальное и висцеральное ожирение, диагностируемые у подавляющего числа обследованных, являются неблагоприятными фактором риска развития сердечно-сосудистых катастроф. Белково-энергетическая недостаточность выявлялась редко, что, по-видимому, указывало на адекватность проводимого большинству пациентов комплексного лечения.

КЛЮЧЕВЫЕ СЛОВА: Ожирение; избыточное питание; мультичастотная биоимпедансометрия; гемодиализ. 